for the disturbance in paralysis agitans is caused by the pyramidal tract working in the absence of extrapyramidal control. It follows that a reduction in the disability caused by the Parkinsonism is in direct proportion to the degree of pyramidal hemiplegia. Because of this, the operation should be considered only in severe cases and preferably if only one side is affected.

(b) All abnormal movements arising as a result of disturbances of the basal ganglia disappear during sleep, but they return on waking, whatever may have been the nature of the sleep. The disturbances are in no way due to psychological causes and are not benefited at all by hypnosis.

\section{Treatment of Ringworm}

Q. -What is the most suecessful treatment for tinea pedis and tinea cruris? Is dithranol ointment safe in a $1 \%$ strength? Is it advisable to do anything about sterilizing clothes, shoes, etc., as was at one time recommended in the Middle East, and, if so, what method would you advise?

A.- Tinea cruris clears rapidly with dithranol, and a $1 \%$ strength is quite safe. Response to treatment of ringworm of the toes is more variable and depends upon the chronicity, the presence or absence of infection of the nails, the degree of secondary eczematization, climate, and other circumstances. Various treatments are appropriate to different stages. It is generally wise to use a variety of local measures at night, turn and turn about, among which dithranol ointment is valuable. as is carbol-fuchsin paint or:

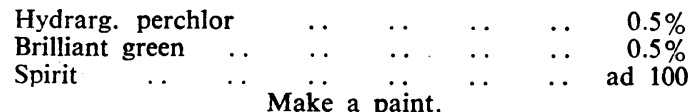

Various other newer fungicides may be used in the morning. The feet should be washed, thoroughly dried, and well powdered. It is wise to sterilize stockings and shoes with formalin and to avoid infecting bath mats, etc., by using slippers for bathing.

\section{Treatment of Callosities}

Q.-What is the best treatment for a callosity on the sole of the foot, opposite the second metatarsal head? The condition may persist for years, and paring, salicylic acid, and rings have little effect.

A.-Callosities of the type described are comrnonly found in association with pes cavus, or with simple flattening of the transverse arch of the foot. There is impairment of the intrinsic muscles with consequent inability of the toes to exercise their important function of sharing the pressure of weight-bearing and walking with the metatarsal heads. Treatment should be directed primarily to the correction of the underlying foot defect. The function of the intrinsic muscles will often be much improved by a suitable course of physiotherapy. This should include intensive foot and toe exercises, and faradic stimulation of the affected muscles. It is important that the exercises be continued at home for an indefinite period.

These measures should in most cases be supplemented by the provision of a suitable support for the transverse arch of the foot. A "sorbo" metatarsal pad on the removable leather insole is satisfactory. The accurate placing of the pad is important: it should lie beneath the necks of the central metatarsals $1 / 2$ inch to $3 / 4$ inch $(1.25-1.85 \mathrm{~cm}$.) behind the metatarsal heads. Paring of these callosities is unlikely to give more than temporary relief unless it is used in conjunction with corrective measures of this kind.

\section{Mud Treatment of Rheumatism}

Q.-Has Pistany mud any special virtues in the treatment of rheumatic complaints? Is there any British product of equal or similar merit? I should be grateful for any other information on this matter.

A.-Pistany mud is the mud deposited at the mouth of the springs of Pistany, a Czechoslovakian spa, and belongs to the group of peloids which includes muds of all kinds and peat. There are similar substances obtainable at most of the British spas, and when applied in conjunction with hot douching and similar procedures they are certainly beneficial in the treatment of joint diseases and other forms of rheumatism, but they are not much used away from the spas. The fact that before the war Pistany mud was readily obtainable on the market and widely advertised made it popular. The action of poultices in general as applied in the home is the same as that of any kind of mud, but special claims are made for alleged radioactivity in some forms of mud. There is as yet no scientific proof that such low-grade radioactivity has anything more than a mild counter-irritant action. Beneficial effects are more likely to be due to the moist heat and the mild pressure exerted by the pack, which aids the absorption of exudates and stimulates the circulation of the affected part. To obtain the full effect of such treatment a course at an appropriate spa is probably desirable.

\section{Angioneurotic Oedema}

Q.-A young man aged 19 suffers annually from hay-fever; he is normal in all other respects. For the past two years, after a course of injections for the hay-fever, he has had frequent attacks of angioneurotic oedema. Repeated examinations have not disclosed the cause, but I think it probable that the hayfever injections have started the attacks. The only treatment that has had any effect is adrenaline injections, but these have been discontinued as the last one precipitated alarming anaphylactic shock. Belladonna, bromides, etc., have failed. Can you suggest any other treatment?

A.- In the absence of a discoverable cause, the best treatment is likely to be symptomatic therapy with one of the antihistaminic drugs, " antistin" or "benadryl." They should be taken as early in the attack as possible, and can be used prophylactically, especially if side-effects are absent or minimal. The first few doses of benadryl should be taken at home, owing to the risk of their making the patient drowsy. Papers on "antistin" and "anthisan" with some comment in a leading article appeared in the Journal of May 8.

\section{Pitressin in Hypertension}

Q.-Is pitressin tartrate uscful for lowering a high blood pressure, and is the reduction so obtained permanent? What are the rules governing its use? Are there dangers associated with its administration?

A.- The writer has never heard of pitressin tartrate and can find no reference to such a substance. Pitressin tannate, a water-soluble compound, has been used, suspended in peanut oil, to control diabetes insipidus (Greene and January, J. Amer. med. Ass., 1940, 115, 1183). The effect of pitressin on the blood pressure in man varies considerably. Melville and Stehle ( $J$. Pharmacol., 1931, 42, 455) showed that the fall in blood pressure produced by pitressin is not due to vascular dilatation but to the constrictor effect on the coronary vessels leading to inability of the heart to maintain the blood pressure. For this reason it should never be used in an attempt to lower the blood pressure.

\section{NOTES AND COMMENTS}

Antrum or Anatomy.-Mr. Desmond W. Conway, Golden Square, W.1, writes: May I draw attention to a possible misprint in the Journal of May 29, which concerns the report of Dr. Julius Lempert's lecture (p. 1045)? He is quoted as saying that his second reason for his use of magnifying glasses, while performing a mastoidal tympanectomy, is "you will see for the first time how beautiful the antrum is." I think it should read as ". . . how beautiful the anatomy is" (of mid-ear). Any btologist performing a radical mastoidectomy will delight in the anatomy of the antrum, but not for reason of its beauty.

Correction.-In our obituary notice of the late Captain E. C. Watson, D.S.O., R.N. (May 29, p. 1054) the phrase " at the close of the war" in the fourth paragraph should have read "at the close of the day."

Ail communications with regard to editorial business should be addressed to THE EDITOR, BRITISH MEDICAL JOURNAL, B.M.A. HOUSE, TAVISTOCK SQUARE, Westcent, London. ORIGINAL ARTICLES AND LETTERS forwarded for publication are understood to be offered to the British Medical Journal alone. Authors desiring REPRINTS should communicate with the Publishing Manager, B.M.A. House, Tavistock Square, W.C.1, on receipt of proofs. ADVERTISEMENTS should be addressed to the Advertisement Manager, B.M.A. House, Tavistock Square, London, W.C.1 (hours 9 a.m. to 5 p.m.). TELEPHONE: EUSTON 2111. TELEGRAMS: Britmedads, Westcent, London. MEMBERS' SUBSCRIPTIONS should be sent to the SECRETARY of the Association. EUSTON 2111. Telegrams : Medisecra, Westcent, London. B.M.A. Scortish OfFICE: 7, Drumsheugh Gardens, Edinburgh. 